\title{
Synthesis of flower-like $\alpha-\mathrm{Fe}_{2} \mathrm{O}_{3}$ and its application in wastewater treatment"
}

\author{
Kun XIE ${ }^{1}$, Xiang-xue WANG ${ }^{2}$, Zheng-jie LIU ${ }^{2}$, Ahmed ALSAEDI ${ }^{3}$, Tasawar HAYAT ${ }^{3}$, Xiang-ke WANG ${ }^{\dagger 2,4}$ \\ $\left({ }^{1}\right.$ Key Laboratory of Water Environment Evolution and Pollution Control in Three Gorges Reservoir, \\ Chongqing Three Gorges University, Chongqing 404100, China) \\ ( ${ }^{2}$ Institute of Plasma Physics, Chinese Academy of Sciences, Hefei 230031, China) \\ $\left({ }^{3}\right.$ NAAM Research Group, Department of Mathematics, Faculty of Science, King Abdulaziz University, Jeddah 21589, Saudi Arabia) \\ ( ${ }^{4}$ Faculty of Engineering, King Abdulaziz University, Jeddah 21589, Saudi Arabia) \\ †E-mail: xkwang@ipp.ac.cn
}

Received May 11, 2014; Revision accepted June 22, 2014; Crosschecked July 18, 2014

\begin{abstract}
The removal of arsenic from aqueous solution is crucial to human health and environmental pollution. Herein, flower-like $\alpha-\mathrm{Fe}_{2} \mathrm{O}_{3}$ nanostructures were synthesized via a template-free microwave-assisted solvothermal technique, and were applied as adsorbents for the removal of arsenic $(\mathrm{As}(\mathrm{V}))$ from aqueous solutions. The results indicated that the synthesized flower-like $\alpha-\mathrm{Fe}_{2} \mathrm{O}_{3}$ showed excellent sorption properties and had a maximum sorption capacity of $47.64 \mathrm{mg} / \mathrm{g}$ for $\mathrm{As}(\mathrm{V})$. Meanwhile, the experimental results of photodegradation of methylene blue (MB) indicated that the as-synthesized flower-like $\alpha-\mathrm{Fe}_{2} \mathrm{O}_{3}$ exhibited very high photocatalytic performance for the photodegradation of $\mathrm{MB}$ and that the as-obtained flower-like $\alpha-\mathrm{Fe}_{2} \mathrm{O}_{3}$ nanostructures were suitable materials in wastewater treatment.
\end{abstract}

Key words: Flower-like $\alpha-\mathrm{Fe}_{2} \mathrm{O}_{3}$, Arsenate, Sorption, Methylene blue (MB), Photodegradation doi:10.1631/jzus.A1400133

Document code: A

CLC number: X52

\section{Introduction}

Environmental pollution of soils and water is a worldwide problem. Common pollutants include organic compounds, such as different kinds of dyes, and heavy metal ions. Dyes are widely used as coloring agents in cosmetics, food, leather, textile, printing, and plastics. Because of their resistance to elimination and degradation, the dyes can remain in aqueous solution for a long time, and dyes and their metabolic byproducts will be mutagenic and cancer-

\footnotetext{
Corresponding author

* Project supported by the National Natural Science Foundation of China (Nos. 21225730 and 91326202), and the Natural Science Foundation of Chongqing Science \& Technology Commission (No. cstc2013jcyjA1225), China

(C) Zhejiang University and Springer-Verlag Berlin Heidelberg 2014
}

ogenic (Jović-Jovičić et al., 2010; Koswojo et al., 2010; Li et al., 2011; Zhang et al., 2013a; 2014). Many techniques such as membrane filtration, biological treatments, sorption, coagulation, flocculation, and advanced oxidation, are used for the treatment of dye-polluted wastewater (Barron-Zambrano et al., 2010; Zermane et al., 2010; Zhang et al., 2013b). Heavy metal ions, such as arsenate ions, are very carcinogenic, harmful, and toxic to human beings (Wu et al., 2013). Arsenic contaminated waters are dangerous to human health because of arsenic's presence in drinking water or food through uptake by plants (Xu et al., 2013). Many people are at risk and tens of thousands suffer from diseases, such as lung and liver cancer, neuropathy, and skin diseases, because they drink water with a high concentration of arsenic (Mohan and Pittman, 2007; Violante et al., 2009). From this, one can see that the elimination of 
arsenic from water is significant for human health and environmental protection.

Fabricating suitable nanomaterials with high surface area is a smart method to eliminate pollutants from aqueous solutions because nanomaterials with high specific surface area can adsorb pollutants, by providing more available sites for binding them and thereby improving sorption/degradation. Micro/nano structured materials, constructed by regularly integrating nanoparticles to microscale materials, have superior ability to remove pollutants compared with nanosized and microsized materials alone. Generally, micro/nano structured materials have the advantages of high activity, large specific surface area, low tendency to agglomerate, and good ease of recovery. Hematite $\left(\alpha-\mathrm{Fe}_{2} \mathrm{O}_{3}\right)$ nanosized materials with different kinds of structures have been synthesized, such as single-crystal nanorings, single-crystal nanorods, and symmetrical dendritic structures. Among these materials, the flower-like $\alpha-\mathrm{Fe}_{2} \mathrm{O}_{3}$ composed of hierarchically nanosized building blocks is one of the best because of its high specific surface areas (Yang et al., 2006; Hu et al., 2007a; Jia et al., 2008; Li et al., 2009; Zhong and Cao, 2010; Sivula et al., 2010; Sun et al., 2010; Wang et al., 2011; Zhang et al., 2013c).

We developed a surfactant-free solvothermal method to synthesize flower-like $\alpha-\mathrm{Fe}_{2} \mathrm{O}_{3}$ composed of 1D hierarchical mesoporous nanoplates. Its specific surface area is about $80 \mathrm{~m}^{2} / \mathrm{g}$, which is higher than those of most hierarchical structures. The advantage of the synthesized material was evidenced from the sorption of arsenate on the as-synthesized sample. As a common material, the hematite material is widely used in the fields of photocatalysis, lithium ion batteries, and sorption (Hu et al., 2007b; Das et al., 2009; Kim et al., 2010). In this study, some controlled experiments on photocatalytic reduction of methylene blue (MB) using the flower-like $\alpha-\mathrm{Fe}_{2} \mathrm{O}_{3}$ as catalyst were also investigated. The experimental results showed possible applications of the as-synthesized material in sorption fields and electron transfer channels as catalyst in real applications.

\section{Experiments}

\subsection{Preparation of $\alpha-\mathrm{Fe}_{2} \mathrm{O}_{3}$}

All the reagents, including ferric chloride $\left(\mathrm{FeCl}_{3} \cdot 6 \mathrm{H}_{2} \mathrm{O}\right)$, urea, and glycol, were purchased from
Tianjin Damao Chemical Reagent Co. Ltd., China and used without any further purification. In a typical step, $7.5 \mathrm{mmol}$ of urea and $5 \mathrm{mmol}$ of $\mathrm{FeCl}_{3} \cdot 6 \mathrm{H}_{2} \mathrm{O}$ were dissolved in $100 \mathrm{ml}$ of glycol, then $40 \mathrm{ml}$ of mixed solution was decanted into a Teflon-lined autoclave. The autoclave was sealed and then placed in a microwave oven which was heated to $160^{\circ} \mathrm{C}$ for $8 \mathrm{~h}$ under microwave heating. Then the sample was cooled to room temperature, and the precipitated $\alpha-\mathrm{Fe}_{2} \mathrm{O}_{3}$ was achieved by centrifugation, then washed with ethanol, and finally dried at $60^{\circ} \mathrm{C}$ for $6 \mathrm{~h}$ in vacuum. The dried powder was heated in a muffle furnace to $500{ }^{\circ} \mathrm{C}$ at a heating rate of $5{ }^{\circ} \mathrm{C} / \mathrm{min}$ and then kept at $500{ }^{\circ} \mathrm{C}$ for $10 \mathrm{~min}$. After the muffle furnace was cooled to room temperature, the red $\alpha-\mathrm{Fe}_{2} \mathrm{O}_{3}$ hierarchical product was obtained.

\subsection{Characterizations}

The X-ray diffraction (XRD) pattern was measured from a D/Max-rB equipped with a rotation anode using $\mathrm{Cu} \mathrm{K} \alpha$ radiation $(\lambda=0.15418 \mathrm{~nm})$. The XRD device was operated at $200 \mathrm{~mA}$ and $40 \mathrm{kV}$. The microstructures and morphology of $\alpha-\mathrm{Fe}_{2} \mathrm{O}_{3}$ were characterized by transmission electron microscopy (TEM) and field emission-scanning electron microscopy (FE-SEM). The $\mathrm{N}_{2}$-Barrett-Emmett-Teller (BET) surface area was calculated from $\mathrm{N}_{2}$ adsorptiondesorption isotherms at $77 \mathrm{~K}$ with a Micromeritics ASAP 2010 system. X-ray photoelectron spectroscopy (XPS) analysis was conducted in a VG Scientific ESCALAB Mark II spectrometer.

\subsection{Experimental process}

A batch method was used to measure arsenic $(\mathrm{As}(\mathrm{V}))$ sorption. The suspensions of $\alpha-\mathrm{Fe}_{2} \mathrm{O}_{3}$ and a known volume of $\mathrm{As}(\mathrm{V})$ solutions were mixed in polyethylene centrifuge tubes. The $\mathrm{pH}$ was revised to the desired values by adding 0.1 or $1.0 \mathrm{~mol} / \mathrm{L} \mathrm{HCl}$ or $\mathrm{NaOH}$. After sorption equilibrium, the solid phase was separated by centrifugation at $10000 \mathrm{r} / \mathrm{min}$ for $30 \mathrm{~min}$. The distribution coefficient $\left(K_{\mathrm{d}}\right)$ and the sorption percent $(\%)$ were calculated from

$$
\begin{gathered}
\text { Sorption percent }=\frac{C_{0}-C_{\mathrm{e}}}{C_{0}} \times 100 \%, \\
K_{\mathrm{d}}=\frac{C_{0}-C_{\mathrm{e}}}{C_{0}} \frac{V}{m},
\end{gathered}
$$


where $m(\mathrm{~g})$ is the mass of solid, $V(\mathrm{ml})$ is the solution volume, $C_{0}$ is the initial concentration $(\mathrm{mg} / \mathrm{L})$, and $C_{\mathrm{e}}$ is the equilibrium concentration $(\mathrm{mg} / \mathrm{L})$.

MB was used as the probe molecule to estimate the photocatalytic activity of $\alpha-\mathrm{Fe}_{2} \mathrm{O}_{3}$ under UV or visible light irradiation. The visible light photocatalytic experiments were conducted in a glass bottle $(100 \mathrm{ml})$ under ambient conditions using a $125 \mathrm{~W}$ mercury lamp as the illuminating source. It was about $5 \mathrm{~cm}$ away from one side of the glass bottle, which was surrounded by a circulating water jacket to avoid the temperature increasing. A cutoff filter was used to eliminate radiations beyond $380 \mathrm{~nm}$ and below $200 \mathrm{~nm}$. During the experiments, the temperature of the MB solution was maintained at $(24 \pm 1){ }^{\circ} \mathrm{C}$ and the $\mathrm{pH}$ was 5.3. $1.0 \mathrm{mg}$ of $\mathrm{MB}$ was dispersed in $100 \mathrm{ml}$ water to achieve a $10 \mathrm{mg} / \mathrm{L} \mathrm{MB}$ aqueous solution. That solution was exposed to the simulated light with continuous magnetic stirring for $240 \mathrm{~min}$ with all other lights eliminated. During the irradiation process, $4 \mathrm{ml}$ aliquot was pipetted at a given interval time and filtered to remove the catalysts and the concentration of MB was analyzed on a Shimadzu UV-2550 spectrophotometer. For the durability measurements of flower-like $\alpha-\mathrm{Fe}_{2} \mathrm{O}_{3}$, five consecutive cycles were carried out. Dark sorption experiments were also carried out to understand the sorption of $\mathrm{MB}$ on flower-like $\alpha-\mathrm{Fe}_{2} \mathrm{O}_{3}$ nanostructures.

\section{Results and discussion}

\subsection{Characterization of flower-like $\alpha-\mathrm{Fe}_{2} \mathrm{O}_{3}$ nanostructures}

The nanostructures and morphologies of the flower-like $\alpha-\mathrm{Fe}_{2} \mathrm{O}_{3}$ were illuminated by FE-SEM. The lower magnification of FE-SEM image (Fig. 1a) showed the multiple flower-like $\alpha-\mathrm{Fe}_{2} \mathrm{O}_{3}$ nanostructures, which maintained well-preserved hierarchical nanostructures with diameters of $1-2 \mu \mathrm{m}$. A representative flower-like nanostructure is shown in the magnified FE-SEM image (Fig. 1b), which indicates that the exterior of the flower-like hierarchical nanostructure was composed of multiple randomly assembled irregular-shaped sheets with a thickness of about $30 \mathrm{~nm}$, as well as loose and cross-linked interiors.

More detailed information of flower-like $\alpha$ $\mathrm{Fe}_{2} \mathrm{O}_{3}$ nanocrystals was provided by TEM. A repre- sentative TEM image of the as-obtained material at a low magnification (Fig. 1c) illustrates that the $\alpha$ $\mathrm{Fe}_{2} \mathrm{O}_{3}$ consisted of many randomly thin nanosheets. Fig. 1d displays a high-magnification TEM image of a flower-like $\alpha-\mathrm{Fe}_{2} \mathrm{O}_{3}$ hierarchical nanostructure, indicating that the structures of the flower-like $\alpha$ $\mathrm{Fe}_{2} \mathrm{O}_{3}$ were very loose, and the nanosheets were composed of irregular-shaped nanoparticles. Some pale areas between the dark nanoparticles indicate porous nanostructures of the nanosheets. The high resolution TEM (HR-TEM) image of the flower-like $\alpha-\mathrm{Fe}_{2} \mathrm{O}_{3}$ hierarchical nanostructures (the inset of Fig. 1d) shows the lattice image obtained at the edge of the sample. The (012) $d$ spacing of the $\alpha-\mathrm{Fe}_{2} \mathrm{O}_{3}$ was found from the typical lattice fringe spacing $(0.370 \mathrm{~nm})$, clearly indicating that the nanostructures consisted of single crystalline nanoparticles.

Fig. 2 shows the corresponding powder XRD pattern of flower-like $\alpha-\mathrm{Fe}_{2} \mathrm{O}_{3}$ nanostructures. The diffraction peaks could be indexed to pure $\alpha-\mathrm{Fe}_{2} \mathrm{O}_{3}$ (JCPDS No. 80-2377). The intense peaks in the XRD pattern indicate that the flower-like $\alpha-\mathrm{Fe}_{2} \mathrm{O}_{3}$ nanostructures were well crystallized. Moreover, no impurity peaks were found in the XRD pattern, pointing to the high purity of the $\alpha-\mathrm{Fe}_{2} \mathrm{O}_{3}$.

The $\mathrm{N}_{2}$ adsorption-desorption isotherms (Fig. 3) were measured to calculate the specific surface area and pore volume of as-obtained flower-like $\alpha-\mathrm{Fe}_{2} \mathrm{O}_{3}$ hierarchical structures. The pore size distribution showed that the average pore of the $\alpha-\mathrm{Fe}_{2} \mathrm{O}_{3}$ was

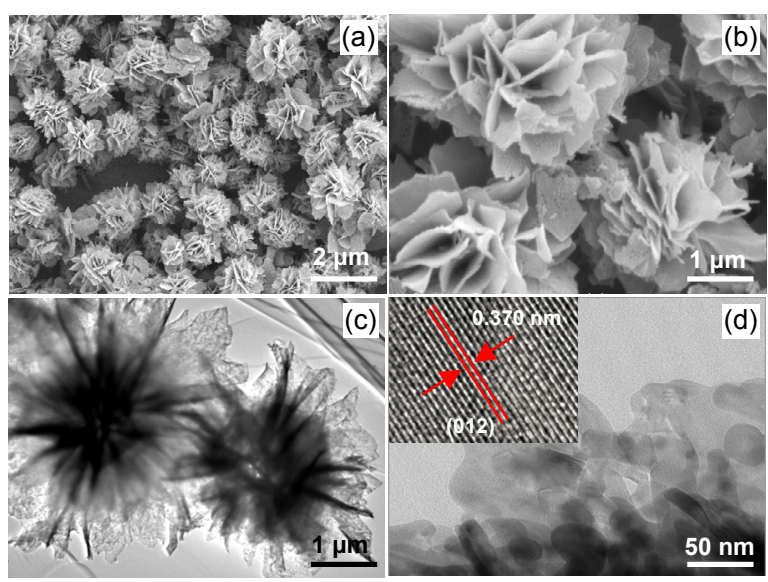

Fig. 1 SEM images of flower-like $\alpha-\mathrm{Fe}_{2} \mathrm{O}_{3}$ nanostructures (a) Lower magnification; (b) Higher magnification; (c) TEM image of flower-like $\alpha-\mathrm{Fe}_{2} \mathrm{O}_{3}$ nanostructures; (d) Higher magnification images of flower-like $\alpha-\mathrm{Fe}_{2} \mathrm{O}_{3}$ nanostructure (the inset is the corresponding HR-TEM image) 


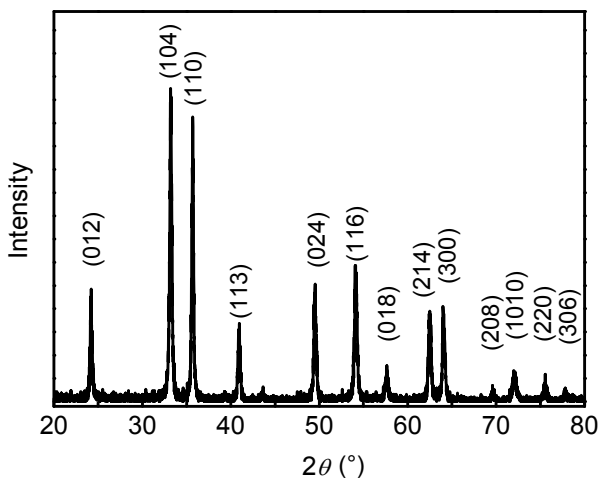

Fig. 2 XRD pattern of flower-like $\alpha-\mathrm{Fe}_{2} \mathrm{O}_{3}$
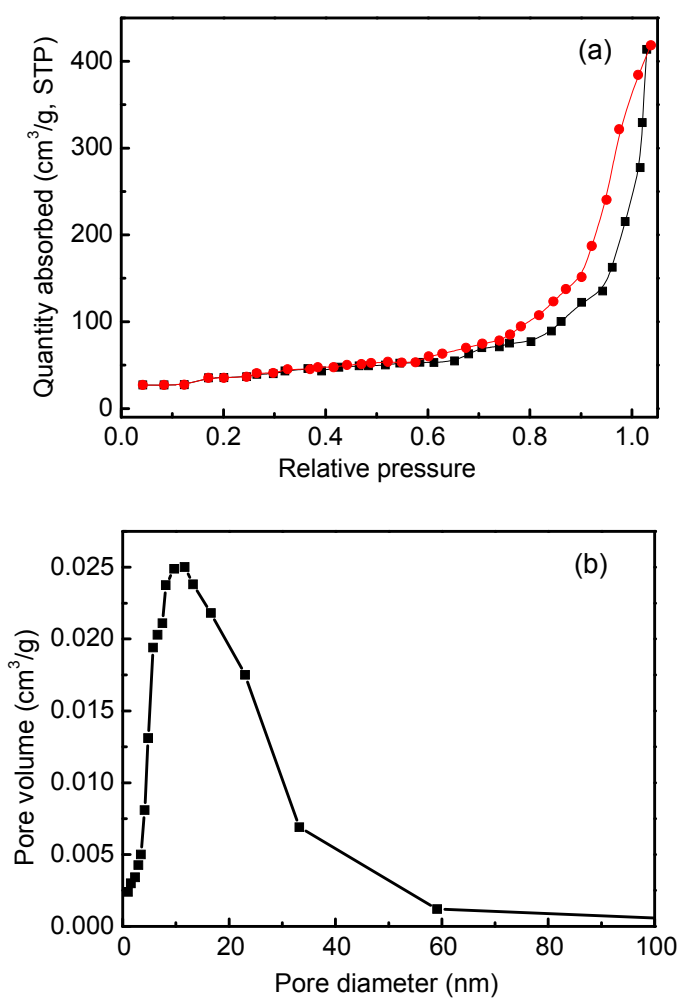

Fig. $3 \mathrm{~N}_{2}$ adsorption-desorption isotherm (a) and pore size distribution (b) of the flower-like $\alpha-\mathrm{Fe}_{2} \mathrm{O}_{3}$ nanostructures

about $4-50 \mathrm{~nm}$. The BET specific surface area obtained from the $\mathrm{N}_{2}$ adsorption was $80 \mathrm{~m}^{2} / \mathrm{g}$, which was larger than that of the commercial $\alpha-\mathrm{Fe}_{2} \mathrm{O}_{3}$ structures $\left(17 \mathrm{~m}^{2} / \mathrm{g}\right)$ (not given in Fig. 3). The porous framework and large surface area of the flower-like $\alpha-\mathrm{Fe}_{2} \mathrm{O}_{3}$ hierarchical structure provide a more efficient transport pathway to the interior voids, which is useful for possible applications in real wastewater treatment.

\section{2 $\mathrm{As}(\mathrm{V})$ sorption}

\subsubsection{Time-dependent sorption}

The sorption of $\mathrm{As}(\mathrm{V})$ on flower-like $\alpha-\mathrm{Fe}_{2} \mathrm{O}_{3}$ nanostructures as a function of contact time was investigated. As shown in Fig. 4a, the sorption of As(V) on $\alpha-\mathrm{Fe}_{2} \mathrm{O}_{3}$ occurred quickly and $8 \mathrm{~h}$ of contact time was enough to achieve equilibrium. The fast $\mathrm{As}(\mathrm{V})$ sorption at the beginning of the contact time was attributed to the rapid diffusion of $\mathrm{As}(\mathrm{V})$ from the aqueous solution to the external surfaces of $\alpha-\mathrm{Fe}_{2} \mathrm{O}_{3}$. Then the sorption achieved equilibrium. From the above results, $24 \mathrm{~h}$ was chosen in the following sorption experiments.

A pseudo-second-order rate equation was applied to simulate the sorption of $\mathrm{As}(\mathrm{V})$ on $\alpha-\mathrm{Fe}_{2} \mathrm{O}_{3}(\mathrm{Li}$ et al., 2011):

$$
\frac{t}{q_{t}}=\frac{1}{2 k^{\prime} q_{\mathrm{e}}^{2}}+\frac{1}{q_{\mathrm{e}}} t
$$

where $q_{t}(\mathrm{mg} / \mathrm{g})$ is the amount of $\mathrm{As}(\mathrm{V})$ adsorbed on $\alpha-\mathrm{Fe}_{2} \mathrm{O}_{3}$ at time $t(\mathrm{~h}), q_{\mathrm{e}}$ is the amount of $\mathrm{As}(\mathrm{V})$ adsorbed per weight of $\alpha-\mathrm{Fe}_{2} \mathrm{O}_{3}(\mathrm{mg} / \mathrm{g})$ after equilibrium, and $k^{\prime}(\mathrm{g} /(\mathrm{mg} \cdot \mathrm{h}))$ is the rate constant of the pseudosecond-order kinetics. The $k^{\prime}(12.86 \mathrm{~g} /(\mathrm{mg} \cdot \mathrm{h}))$ and $q_{\mathrm{e}}$ $(14.47 \mathrm{mg} / \mathrm{g})$ values are calculated from the slope and intercept of the linear plot of $t / q_{t}$ vs. $t$ (Fig. 4). The correlation coefficient $\left(R^{2}\right)$ of the linear plot is 0.99 (very close to 1), indicating that the kinetic sorption of $\mathrm{As}(\mathrm{V})$ on $\alpha-\mathrm{Fe}_{2} \mathrm{O}_{3}$ is a pseudo-second-order rate model.

\subsubsection{Effect of $\mathrm{pH}$}

The $\mathrm{pH}$ of the $\mathrm{As}(\mathrm{V})$ solution is an important factor influencing $\mathrm{As}(\mathrm{V})$ sorption. The impact of $\mathrm{pH}$ on $\mathrm{As}(\mathrm{V})$ sorption by flower-like $\alpha-\mathrm{Fe}_{2} \mathrm{O}_{3}$ nanostructures at $\mathrm{pH} 1.0-12.0$ is shown in Fig. 4c. $\mathrm{As}(\mathrm{V})$ sorption on $\alpha-\mathrm{Fe}_{2} \mathrm{O}_{3}$ maintains about $94 \%$ at $\mathrm{pH} 1.0-4.4$ and then decreases quickly at $\mathrm{pH} 4.4-8.0$. At $\mathrm{pH}>8.0, \mathrm{As}(\mathrm{V})$ sorption decreases slightly with increasing $\mathrm{pH}$. The zero point charge $\left(\mathrm{pH}_{\mathrm{zpc}}\right)$ of $\alpha-\mathrm{Fe}_{2} \mathrm{O}_{3}$ and the species of $\mathrm{As}(\mathrm{V})$ are the main parameters controlling the sorption of $\mathrm{As}(\mathrm{V})$ on $\alpha-\mathrm{Fe}_{2} \mathrm{O}_{3}$. As shown in Fig. 5a, the $\mathrm{pH}_{\mathrm{zpc}}$ of $\alpha-\mathrm{Fe}_{2} \mathrm{O}_{3}$ is about 4.4. The major $\mathrm{As}(\mathrm{V})$ species in different $\mathrm{pH}$ ranges are also included in Fig. 5b. As the solution $\mathrm{pH}$ increases from an acidic region to an alkaline region, $\mathrm{As}(\mathrm{V})$ 
ions in solution exist mainly as $\mathrm{H}_{3} \mathrm{AsO}_{4}$ at $\mathrm{pH}<2.2$ $\left(\mathrm{p} K_{\mathrm{a} 1}\right), \mathrm{H}_{2} \mathrm{AsO}_{4}{ }^{-}$at $\mathrm{pH}$ 2.2-6.98 $\left(\mathrm{p} K_{\mathrm{a} 2}\right), \mathrm{HAsO}_{4}{ }^{2-}$ at $\mathrm{pH}$ 6.98-11.5 (pK $\left.K_{\mathrm{a} 3}\right)$, and $\mathrm{AsO}_{4}{ }^{3-}$ at $\mathrm{pH}>11.5$ (Zhu et al., 2009; Chang et al., 2010). When the $\mathrm{pH}$ is below the isoelectric point of $\alpha-\mathrm{Fe}_{2} \mathrm{O}_{3}$, the surface of $\alpha-\mathrm{Fe}_{2} \mathrm{O}_{3}$ will be positively charged and favorable for $\mathrm{As}(\mathrm{V})$ sorption. As(V) ions are easily adsorbed on the $\alpha-\mathrm{Fe}_{2} \mathrm{O}_{3}$ hierarchical microspheres surface in the low $\mathrm{pH}$ range due to strong electrostatic attraction between $\mathrm{As}(\mathrm{V})$ and $\alpha-\mathrm{Fe}_{2} \mathrm{O}_{3}$. As $\mathrm{pH}$ increases, the
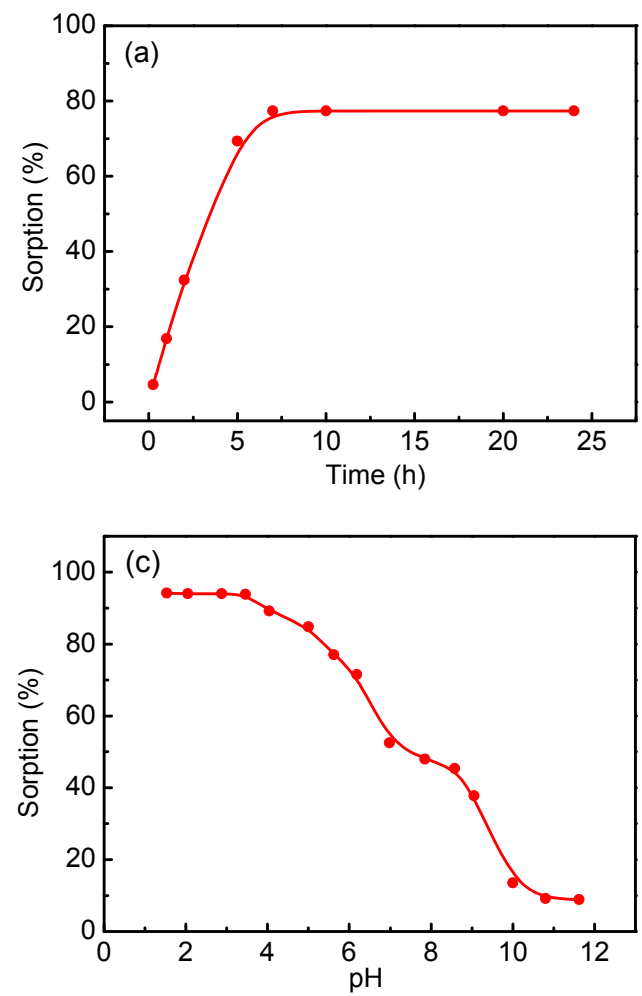

$\alpha-\mathrm{Fe}_{2} \mathrm{O}_{3}$ surface becomes less positively charged, and the interaction between $\alpha-\mathrm{Fe}_{2} \mathrm{O}_{3}$ and $\mathrm{As}(\mathrm{V})$ becomes less and changes to a repulsive force at $\mathrm{pH}>\mathrm{pH}_{\mathrm{zpc}}$, resulting in a significant decrease of $\mathrm{As}(\mathrm{V})$ sorption. The relationship of the electrostatic force between $\mathrm{As}(\mathrm{V})$ ions and $\alpha-\mathrm{Fe}_{2} \mathrm{O}_{3}$ explains the influence of $\mathrm{pH}$ on $\mathrm{As}(\mathrm{V})$ sorption. This has been well described in previous studies concerning $\mathrm{As}(\mathrm{V})$ sorption on other adsorbents (Zhu et al., 2009; Chang et al., 2010; Sheng et al., 2012).
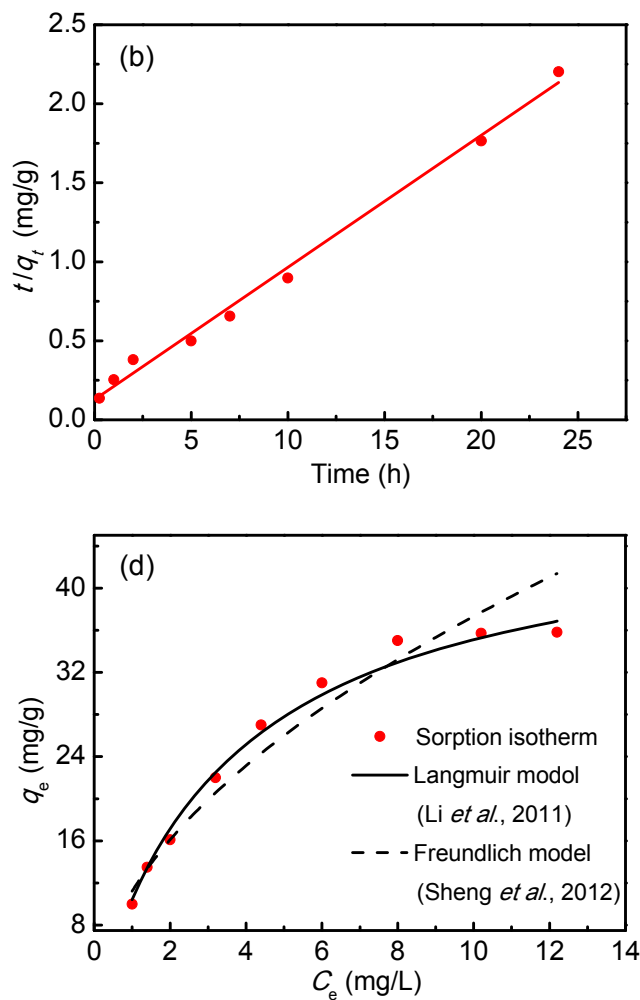

Fig. $4 \mathrm{As}(\mathrm{V})$ sorption on flower-like $\alpha-\mathrm{Fe}_{2} \mathrm{O}_{3}$ nanostructures

(a) Effect of time $(m / V=0.6 \mathrm{~g} / \mathrm{L}, \mathrm{pH}=5.0)$; (b) Pseudo-second-order kinetics for the sorption of As(V) on flower-like $\alpha-\mathrm{Fe}_{2} \mathrm{O}_{3}$ nanostructures $(m / V=0.6 \mathrm{~g} / \mathrm{L}, \mathrm{pH}=5.0)$; (c) Effect of $\mathrm{pH}(\mathrm{m} / V=0.6 \mathrm{~g} / \mathrm{L})$; (d) Sorption isotherms of As(V) on flower-like $\alpha-\mathrm{Fe}_{2} \mathrm{O}_{3}$ nanostructures $(m / V=0.6 \mathrm{~g} / \mathrm{L}, \mathrm{pH}=5.0)$
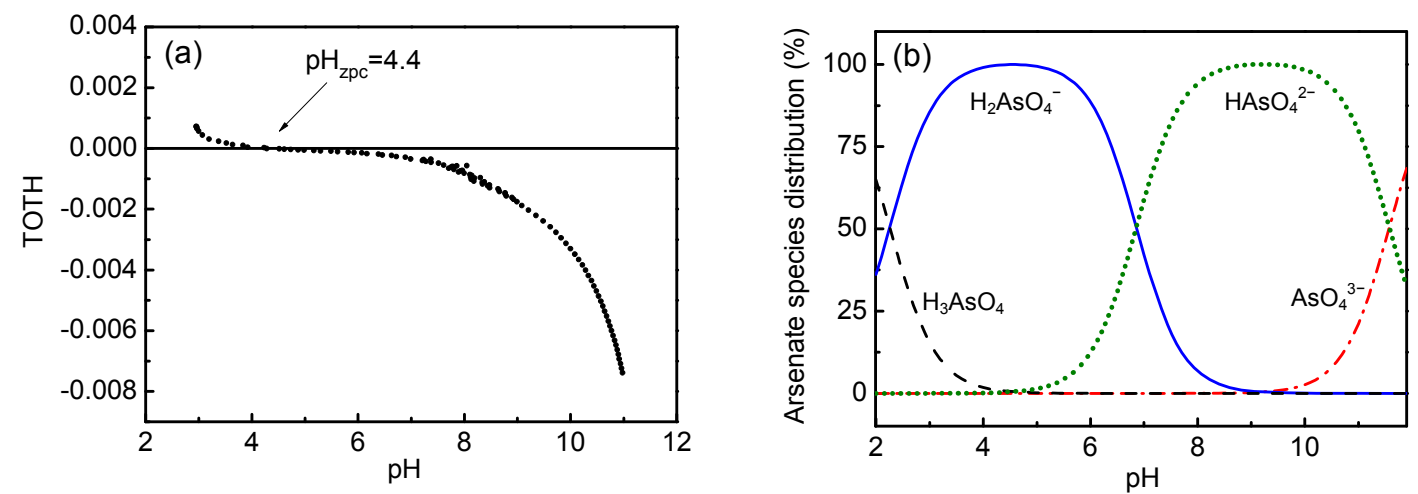

Fig. 5 Zeta potential of $\alpha-\mathrm{Fe}_{2} \mathrm{O}_{3}$ (a) and speciation diagram of arsenate (b)

TOTH: the total concentration of consumed protons in the titration process 


\subsubsection{Sorption isotherms}

The sorption isotherms of $\mathrm{As}(\mathrm{V})$ on flower-like $\alpha-\mathrm{Fe}_{2} \mathrm{O}_{3}$ nanostructures are shown in Fig. 4d. The Freundlich (Li et al., 2011) and Langmuir (Sheng et $a l ., 2012)$ models are used to simulate $\mathrm{As}(\mathrm{V})$ interaction on $\alpha-\mathrm{Fe}_{2} \mathrm{O}_{3}$. The Freundlich model is described by

$$
q_{\mathrm{e}}=k_{\mathrm{F}} C_{\mathrm{e}}^{n}
$$

and the Langmuir model can be expressed as

$$
q_{\mathrm{e}}=\frac{b q_{\mathrm{max}} C_{\mathrm{e}}}{1+b C_{\mathrm{e}}}
$$

where $k_{\mathrm{F}}\left(\mathrm{mg}^{1-n} \cdot \mathrm{L}^{n} / \mathrm{g}\right)$ represents the sorption capacity when the metal ion equilibrium concentration equals to 1 and $n$ represents the degree of dependence of sorption with equilibrium concentration, $C_{\mathrm{e}}$ is the equilibrium concentration of $\mathrm{As}(\mathrm{V})$ in the supernatant $(\mathrm{mg} / \mathrm{L}), q_{\max }$ is the maximum sorption capacity of $\mathrm{As}(\mathrm{V})$ per weight of $\alpha-\mathrm{Fe}_{2} \mathrm{O}_{3}(\mathrm{mg} / \mathrm{g})$, and $b$ represents the Langmuir sorption constant $(\mathrm{L} / \mathrm{mg})$. The Freundlich constant $k$ is correlated to the relative sorption capacity of $\operatorname{As}(\mathrm{V})(\mathrm{mg} / \mathrm{g})$, and $1 / n$ is the sorption intensity.

The sorption results were regressively modeled by the Langmuir and Freundlich models. The parameters are listed in Table 1. The higher $R$ value of the Langmuir model indicated that the sorption isotherms were better simulated by the Langmuir model than that by the Freundlich model. The calculated value of $q_{\text {max }}$ was $47.62 \mathrm{mg} / \mathrm{g}$ for $\alpha-\mathrm{Fe}_{2} \mathrm{O}_{3}$, indicating that flower-like $\alpha-\mathrm{Fe}_{2} \mathrm{O}_{3}$ nanostructures had excellent sorption properties. The Freundlich constant $n$ is found to be $0.53(n<1)$, indicating a favorable process of $\mathrm{As}(\mathrm{V})$ sorption on $\alpha-\mathrm{Fe}_{2} \mathrm{O}_{3}$.

Table 1 Langmuir and Freundlich isotherm parameters for $\mathrm{As}(\mathrm{V})$ sorption on flower-like $\alpha-\mathrm{Fe}_{2} \mathrm{O}_{3}$

\begin{tabular}{ccccccc}
\hline \multicolumn{3}{c}{ Langmuir } & & \multicolumn{3}{c}{ Freundlich } \\
\cline { 1 - 5 } \cline { 5 - 6 }$q_{\max }(\mathrm{mg} / \mathrm{g})$ & $b(\mathrm{~L} / \mathrm{mg})$ & $R^{2}$ & & $k_{\mathrm{F}}\left(\mathrm{mg}^{1-n} \cdot \mathrm{L}^{n} / \mathrm{g}\right)$ & $n$ & $R^{2}$ \\
\hline 47.64 & 0.28 & 0.99 & & 11.36 & 0.52 & 0.96 \\
\hline
\end{tabular}

To investigate the sorption mechanism further, as-saturated flower-like $\alpha-\mathrm{Fe}_{2} \mathrm{O}_{3}$ nanostructures were prepared. $\mathrm{As}(\mathrm{V})$ ions were excited predominately as $\mathrm{NaH}_{2} \mathrm{AsO}_{4}$ in aqueous solutions at $\mathrm{pH}=4.4$. The surface of flower-like $\alpha-\mathrm{Fe}_{2} \mathrm{O}_{3}$ was positively charged. Thereby, the electrostatic attraction between the positively charged $\alpha-\mathrm{Fe}_{2} \mathrm{O}_{3}$ samples and the negatively charged $\mathrm{As}(\mathrm{V})$ ions was the main driving force binding the $\mathrm{As}(\mathrm{V})$ ions onto the $\alpha-\mathrm{Fe}_{2} \mathrm{O}_{3}$. The sorption mainly occurred on the surface of $\alpha-\mathrm{Fe}_{2} \mathrm{O}_{3}$ nanostructures. XPS technique was applied to characterize the surface states of $\alpha-\mathrm{Fe}_{2} \mathrm{O}_{3}$ after $\mathrm{As}(\mathrm{V})$ sorption. Fig. 6a shows the full-range XPS spectra of $\alpha-\mathrm{Fe}_{2} \mathrm{O}_{3}$ nanostructures after $\mathrm{As}(\mathrm{V})$ sorption. It displays the binding energies for $\mathrm{C} 1 \mathrm{~s}, \mathrm{O} 1 \mathrm{~s}, \mathrm{As} 3 \mathrm{~d}, \mathrm{Fe} 2 \mathrm{p}$, and As 2p. As shown in Fig. 6a, As(V) element was found in the XPS spectrum. The element mapping indicated that $\mathrm{As}(\mathrm{V})$ was evenly distributed on $\alpha-\mathrm{Fe}_{2} \mathrm{O}_{3}$ nanostructures. As(V) appeared after $\mathrm{As}(\mathrm{V})$ was adsorbed on $\alpha-\mathrm{Fe}_{2} \mathrm{O}_{3}$. The As $3 \mathrm{~d}$ spectrum after $\mathrm{As}(\mathrm{V})$ sorption showed peaks at $45.2 \mathrm{eV}$ and $1327.4 \mathrm{eV}$, which were attributed to $\mathrm{As}(\mathrm{V})-\mathrm{O}$ bonding. Fig. 6d displays the Fe $2 p$ spectrum after As(V) sorption, and no peaks were changed, indicating that the structure of $\alpha-\mathrm{Fe}_{2} \mathrm{O}_{3}$ was not changed after $\mathrm{As}(\mathrm{V})$ sorption.

From the results mentioned above, the sorption mechanism of $\mathrm{As}(\mathrm{V})$ on the flower-like $\alpha-\mathrm{Fe}_{2} \mathrm{O}_{3}$ nanostructures was electrostatic attraction between $\alpha-\mathrm{Fe}_{2} \mathrm{O}_{3}$ and $\mathrm{H}_{2} \mathrm{AsO}_{4}{ }^{-}$species. Electrostatic force played a critical role in sorption.

\subsection{Photocatalysis of MB}

\subsubsection{Degradation efficiency}

The photocatalytic degradation of $\mathrm{MB}$ in four different treatment processes is displayed in Fig. 7a. It can be seen that only $62 \%$ of MB was degraded after $250 \mathrm{~min}$ of continuous visible light irradiation without any catalyst. In the presence of flower-like $\alpha-\mathrm{Fe}_{2} \mathrm{O}_{3}$ nanostructures under the same conditions, almost all of the MB was photocatalytic degraded, suggesting excellent photocatalytic ability of flowerlike $\alpha-\mathrm{Fe}_{2} \mathrm{O}_{3}$ under visible light irradiation. When the test tube was placed in dark surroundings, almost no MB was degraded, indicating that the elimination of MB was mainly caused by photocatalytic degradation rather than adsorption. As comparison, the photocatalytic activity of commercial $\alpha-\mathrm{Fe}_{2} \mathrm{O}_{3}$ was also studied. The results demonstrated that the flower-like 

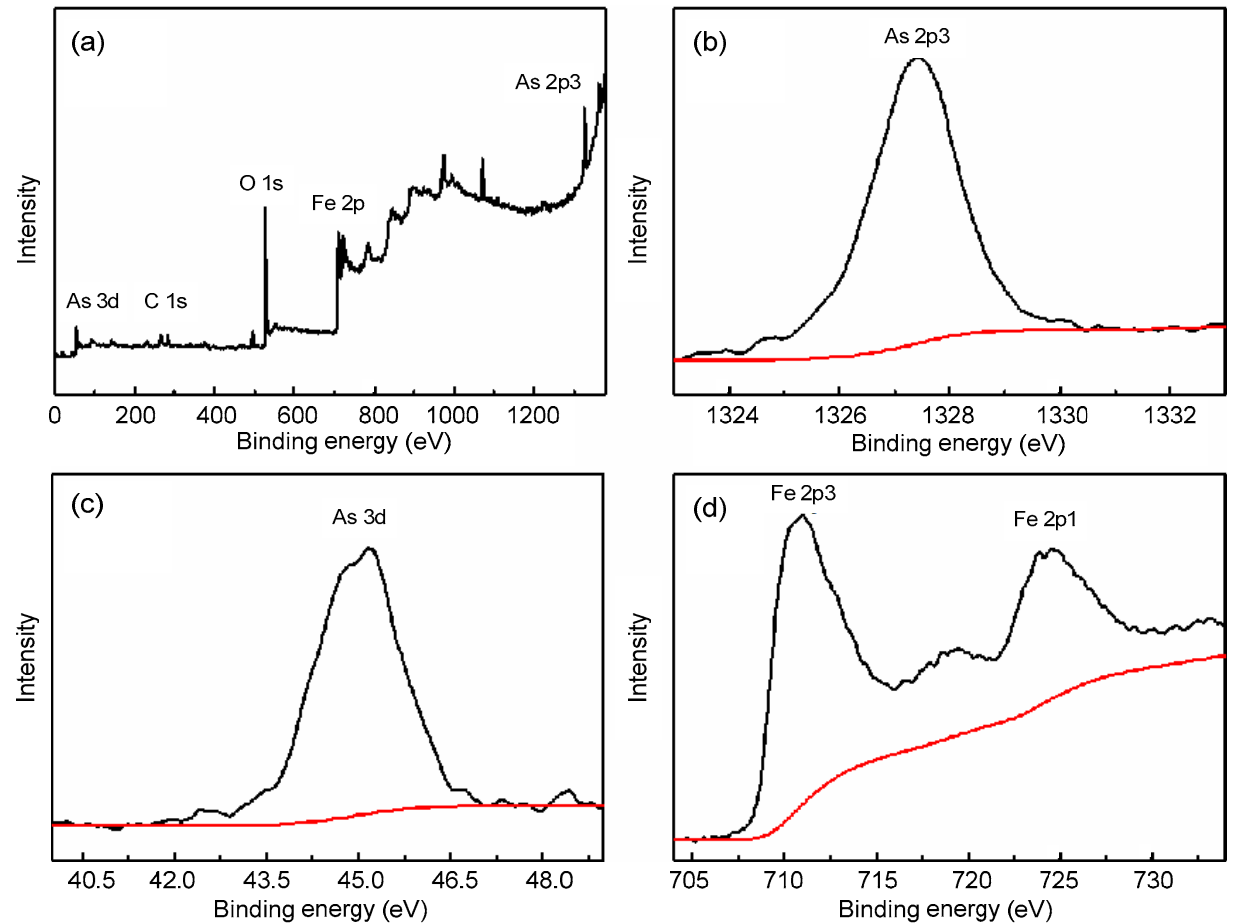

Fig. 6 Full-range XPS spectra of flower-like $\alpha-\mathrm{Fe}_{2} \mathrm{O}_{3}$ nanostructures after $\mathrm{As}(\mathrm{V})$ sorption (a), As 2p XPS spectrum (b), As 3d XPS spectrum(c), and Fe 2p XPS spectrum (d)
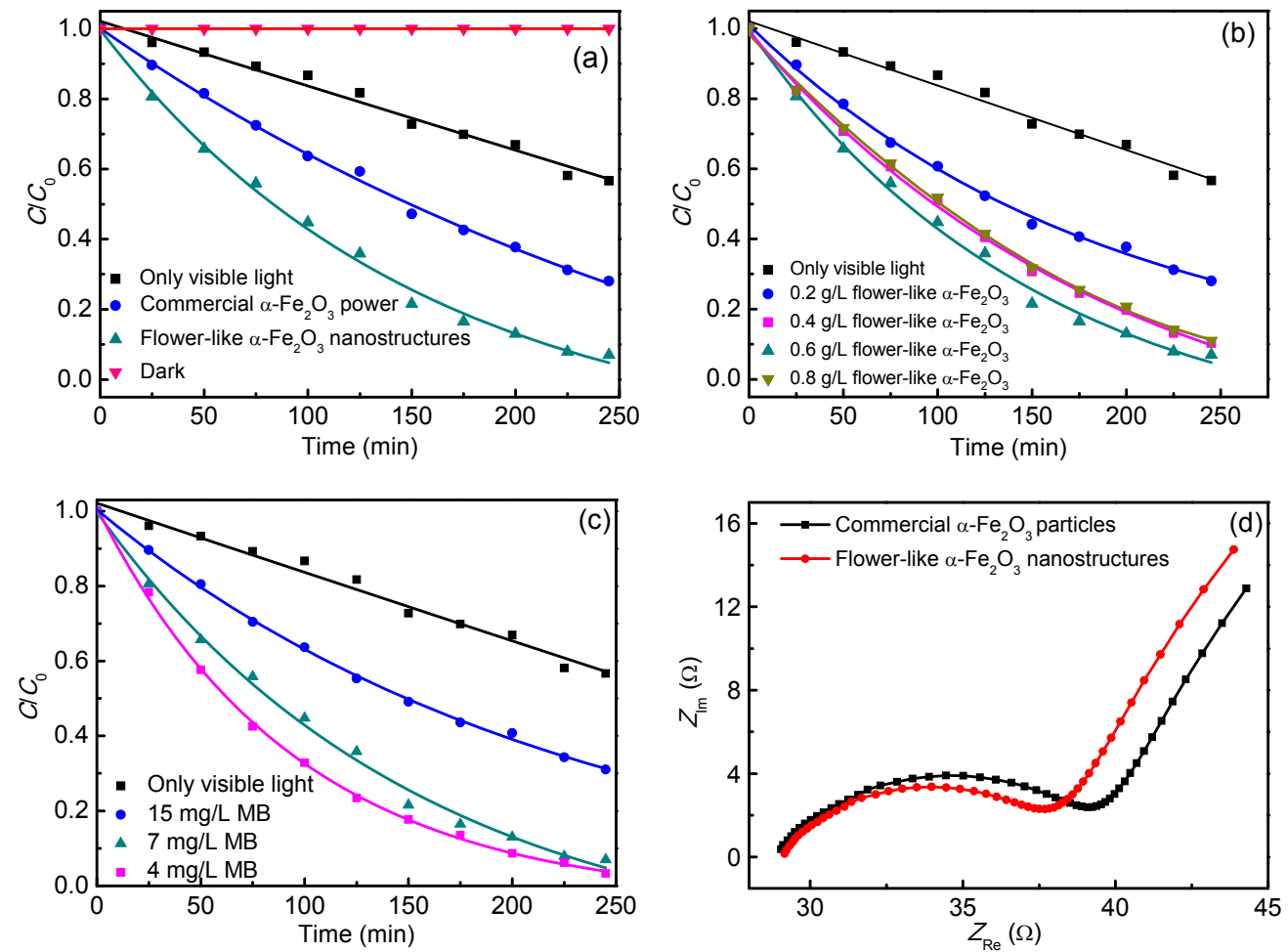

Fig. 7 Photocatalysis of MB

(a) Comparison of change in degradation efficiency (\%) as a function of irradiation time, $C_{[\mathrm{MB}] \text { initial }}=10 \mathrm{mg} / \mathrm{L}, \mathrm{m} / \mathrm{V}=0.6 \mathrm{~g} / \mathrm{L}$;

(b) Effect of photocatalyst dosage on MB degradation $\left(C_{[\mathrm{MB}] \text { initial }}=10 \mathrm{mg} / \mathrm{L}\right)$; (c) Effect of MB concentration on MB degradation $(m / V=0.6 \mathrm{~g} / \mathrm{L})$; (d) EIS changes of flower-like $\alpha-\mathrm{Fe}_{2} \mathrm{O}_{3}$ and commercial $\alpha-\mathrm{Fe}_{2} \mathrm{O}_{3}$ powder electrodes 
$\alpha-\mathrm{Fe}_{2} \mathrm{O}_{3}$ has higher photocatalytic ability than commercial $\alpha-\mathrm{Fe}_{2} \mathrm{O}_{3}$.

\subsubsection{Effect of photocatalyst dosage on MB degradation}

Photocatalysis of MB $(10 \mathrm{mg} / \mathrm{L})$ was measured with four different catalyst contents ranging from 0.2 to $0.8 \mathrm{~g} / \mathrm{L}$. As can be seen from Fig. $7 \mathrm{~b}$, the photocatalytic degradation of MB increased with increasing catalyst content from 0.2 to $0.6 \mathrm{~g} / \mathrm{L}$. With increasing amount of catalyst, the quantity of photons and the $\mathrm{MB}$ adsorbed on $\alpha-\mathrm{Fe}_{2} \mathrm{O}_{3}$ increased and consequently increased the $\mathrm{MB}$ degradation. However, the further increase in $\alpha-\mathrm{Fe}_{2} \mathrm{O}_{3}$ concentration to $0.8 \mathrm{~g} / \mathrm{L}$ resulted in a decrease of the efficiency of MB degradation. Consequently, higher concentrations of $\alpha-\mathrm{Fe}_{2} \mathrm{O}_{3}$ revealed a passive effect on the photocatalytic degradation of MB. The available active sites increased with increasing amount of $\alpha-\mathrm{Fe}_{2} \mathrm{O}_{3}$; however, the photoactivated volume of solution and the light penetration shrank (Chang et al., 2010). It can also be attributed to the increased opacity of the suspension bringing a shielding effect and light scattering (Chang et al., 2010). In addition, the decrease of degradation at higher catalyst concentrations may be due to the deactivation of activated MB molecules through conflict with ground state molecules (Chang et al., 2010; Zhao et al., 2012). Herein, the optimum concentration of catalyst was chosen as $0.6 \mathrm{~g} / \mathrm{L}$, to assure the absorption of light photons for efficient photomineralization and also to avoid unnecessary excess.

\subsubsection{Effect of the initial concentration of MB}

Fig. 7c shows the photocatalytic degradation of $\mathrm{MB}$ at different initial concentrations at a $\alpha-\mathrm{Fe}_{2} \mathrm{O}_{3}$ content of $50 \mathrm{mg} / \mathrm{L}$. One can see from Fig. $7 \mathrm{c}$ that the photodegradation efficiency decreases with increasing MB concentration. The degradation rate is related to the formation of free hydroxyl radicals on the surface of $\alpha-\mathrm{Fe}_{2} \mathrm{O}_{3}$ and the reaction of free hydroxyl radicals with $\mathrm{MB}$ molecules. With increasing $\mathrm{MB}$ concentration, the probability of $-\mathrm{OH}$ radical reaction with $\mathrm{MB}$ molecules increases. The available active sites on the $\alpha-\mathrm{Fe}_{2} \mathrm{O}_{3}$ surface are replaced or overlaid by MB molecules. The production of $-\mathrm{OH}$ radicals decreases as there are fewer available active sites for the regeneration of $-\mathrm{OH}$ radicals. Another important reason is that the high $\mathrm{MB}$ concentration shadows the light, making it difficult for visible light to trigger the catalyst. Thereby, the concentration of hydroxyl free radicals decreases and the photocatalytic degradation decreases (Zhang et al., 2013c).

3.3.4 Electrochemical impedance spectroscopy (EIS) changes of flower-like $\alpha-\mathrm{Fe}_{2} \mathrm{O}_{3}$ nanostructures and the commercial $\alpha-\mathrm{Fe}_{2} \mathrm{O}_{3}$ powder electrodes

Fig. 7d shows the EIS of the flower-like $\alpha-\mathrm{Fe}_{2} \mathrm{O}_{3}$ nanostructures and the commercially available $\alpha$ $\mathrm{Fe}_{2} \mathrm{O}_{3}$ samples. One can see that both samples have similar plots with one semicircle in the high frequency region and an inclined straight line in the low frequency. It is clear that the semicircle radius of the flower-like $\alpha-\mathrm{Fe}_{2} \mathrm{O}_{3}$ sample is much smaller than that of a commercial $\alpha-\mathrm{Fe}_{2} \mathrm{O}_{3}$ powder sample. It can be deduced that the flower-like $\alpha-\mathrm{Fe}_{2} \mathrm{O}_{3}$ nanostructures improve the conductivity of the electrode. The designed hierarchical nanostructure is important for the enhancement of electron transport. The netlike substructures of the plates in the flower-like $\alpha-\mathrm{Fe}_{2} \mathrm{O}_{3}$ material improve electron transport in the electrontransport channels. For the commercial $\alpha-\mathrm{Fe}_{2} \mathrm{O}_{3}$ powder sample, the transfer of electrons is difficult because of contact resistance between the particles.

\subsubsection{Reuse of photocatalyst}

The reusability of the catalyst is important for efficiency. For an environmentally friendly approach, reusability is desired for it makes the process free of waste and also reduces its operational cost. To explore the reusability potential of the flower-like $\alpha-\mathrm{Fe}_{2} \mathrm{O}_{3}$, it was recovered from the reaction mixture through filtration. The catalyst was then washed with distilled water and dried in an oven at $60{ }^{\circ} \mathrm{C}$. The recovered catalyst was then reused for the degradation of MB under the same reaction conditions as mentioned above. The catalytic activity of $\alpha-\mathrm{Fe}_{2} \mathrm{O}_{3}$ was tested for 5 cycles. As can be seen from Fig. 8, after being reused for 5 times, the $\alpha-\mathrm{Fe}_{2} \mathrm{O}_{3}$ catalyst still preserved its photocatalytic behavior and the dye degradation efficiency was almost the same. This reusability of $\alpha-\mathrm{Fe}_{2} \mathrm{O}_{3}$ is attributed to its stability and resistance to photocorrosion. Thus, because of the recyclable nature of $\alpha-\mathrm{Fe}_{2} \mathrm{O}_{3}$, it can be used as an efficient catalyst for the degradation of dyes. 


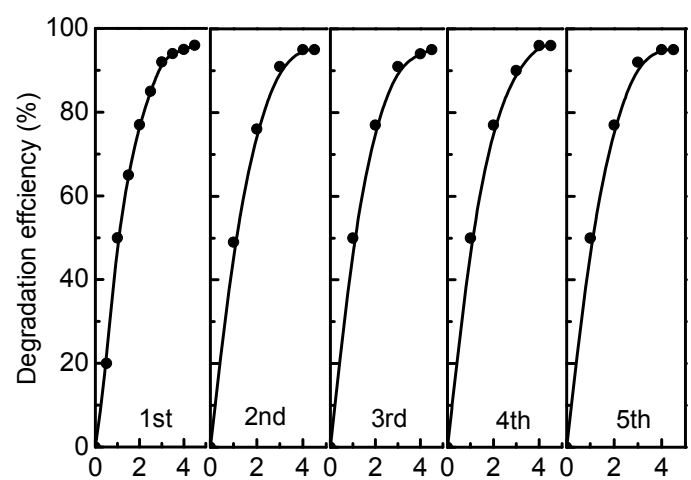

Fig. 8 Reusability of $\alpha-\mathrm{Fe}_{2} \mathrm{O}_{3}$ catalyst for the degradation of MB for 5 cycles

\section{Conclusions}

Flower-like $\alpha-\mathrm{Fe}_{2} \mathrm{O}_{3}$ nanostructures were synthesized using a low-cost solvothermal method. These flower-like $\alpha-\mathrm{Fe}_{2} \mathrm{O}_{3}$ nanostructures had high specific surface area and abundant hydroxyl groups and showed high sorption capacity for $\mathrm{As}(\mathrm{V})$ ions. The sorption mechanism of $\mathrm{As}(\mathrm{V})$ on the flower-like $\alpha-\mathrm{Fe}_{2} \mathrm{O}_{3}$ nanostructures was confirmed as an electrostatic force between $\alpha-\mathrm{Fe}_{2} \mathrm{O}_{3}$ and $\mathrm{As}(\mathrm{V})$ species. The photocatalytic degradation of $\mathrm{MB}$ was dependent on the hierarchical flower-like $\alpha-\mathrm{Fe}_{2} \mathrm{O}_{3}$ nanostructures. The initial MB concentration and the content of $\alpha-\mathrm{Fe}_{2} \mathrm{O}_{3}$ affected the photocatalytic degradation of MB markedly. The remarkable improvement in sorption and photocatalytic degradation properties was attributed to the flower-like structures. To sum up, the as-synthesized flower-like structures are a benefit for real applications in the cleanup of wastewater pollution.

\section{References}

Barron-Zambrano, J., Szygula, A., Ruiz, M., et al., 2010. Biosorption of reactive black from aqueous solutions by chitosan: column studies. Journal of Environmental Management, 91(12):2669-2675. [doi:10.1016/j.jenvman. 2010.07.033]

Chang, Q., Lin, W., Ying, W., 2010. Preparation of ironimpregnated granular activated carbon for arsenic removal from drinking water. Journal of Hazardous Materials, 184(1-3):515-522. [doi:10.1016/j.jhazmat.2010.08. 066]

Das, M., Mishra, D., Dhak, P., et al., 2009. Biofunctionalized, phosphonate-grafted, ultrasmall iron oxide nanoparticles for combined targeted cancer therapy and multimodal imaging. Small, 5(24):2883-2893. [doi:10.1002/smll. 200901219]

Hu, X.L., Yu, J.C., Gong, J.M., 2007a. Fast production of self-assembled hierarchicalr- $\mathrm{Fe}_{2} \mathrm{O}_{3}$ nanoarchitectures. The Journal of Physical Chemistry C, 111(30):1118011185. [doi:10.1021/jp073073e]

Hu, X.L., Yu, J.C., Gong, J.M., et al., 2007b. $\alpha-\mathrm{Fe}_{2} \mathrm{O}_{3}$ nanorings prepared by a microwave-assisted hydrothermal process and their sensing properties. Advanced Materials, 19(17):2324-2329. [doi:10.1002/adma.200602176]

Jia, C.J., Sun, L.D., Luo, F., et al., 2008. Large-scale synthesis of single-crystalline iron oxide magnetic nanorings. Journal of the American Chemical Society, 130(50): 16968-16977. [doi:10.1021/ja805152t]

Jović-Jovičić, N., Milutinović-Nikolić, A., Banković, P., et al., 2010. Organo-inorganic bentonite for simultaneous adsorption of Acid Orange 10 and lead ions. Applied Clay Science, 47(3-4):452-456. [doi:10.1016/j.clay.2009.11. 005]

Kim, H.S., Piao, Y., Kang, S.H., et al., 2010. Uniform hematite nanocapsules based on an anode material for lithium ion batteries. Electrochemistry Communications, 12(3):382385. [doi:10.1016/j.elecom.2009.12.040]

Koswojo, R., Utomo, R.P., Ju, Y.H., et al., 2010. Acid Green 25 removal from wastewater by organo-bentonite from Pacitan. Applied Clay Science, 48(1-2):81-86. [doi:10. 1016/j.clay.2009.11.023]

Li, J.X., Chen, S.Y., Sheng, G.D., et al., 2011. Effect of surfactants on $\mathrm{Pb}$ (II) adsorption from aqueous solutions using oxidized multiwall carbon nanotubes. Chemical Engineering Journal, 166(2):551-558. [doi:10.1016/j.cej. 2010.11.018]

Li, Z.M., Lai, X.Y., Wang, H., et al., 2009. Direct hydrothermal synthesis of single-crystalline hematite nanorods assisted by 1,2-propanediamine. Nanotechnology, 20(24): 245603-245613. [doi:10.1088/0957-4484/20/24/245603]

Mohan, D., Pittman, C.U.Jr., 2007. Arsenic removal from water/wastewater using adsorbents - a critical review. Journal of Hazardous Materials, 142(1-2):1-53. [doi:10. 1016/j.jhazmat.2007.01.006]

Sheng, G.D., Li, Y.M., Yang, X., et al., 2012. Efficient removal of arsenate by versatile magnetic graphene oxide composites. RSC Advances, 2(32):12400-12407. [doi:10. $1039 / \mathrm{c} 2 \mathrm{ra} 21623 \mathrm{j}]$

Sivula, K., Zboril, R., Formal, R.L., 2010. Photoelectrochemical water splitting with mesoporous hematite prepared by a solution-based colloidal approach. Journal of the American Chemical Society, 132(21):7436-7444. [doi:10. 1021/ja101564f]

Sun, B., Horvat, J., Kim, H.S., et al., 2010. Synthesis of mesoporousr- $-\mathrm{Fe}_{2} \mathrm{O}_{3}$ nanostructures for highly sensitive gas sensors and high capacity anode materials in lithium ion batteries. The Journal of Physical Chemistry $C$, 114(44):18753-18761. [doi:10.1021/jp102286e]

Violante, A., Pucci, M., Cozzolino, V., et al., 2009. Sorption/ 
desorption of arsenate on/from Mg-Al layered double hydroxides: influence of phosphate. Journal of Colloid and Interface Science, 333(1):63-70. [doi:10.1016/j.jcis. 2009.01.004]

Wang, L.L., Fei, T., Lou, Z., et al., 2011. Three-dimensional hierarchical flowerlike $\alpha-\mathrm{Fe}_{2} \mathrm{O}_{3}$ nanostructures: synthesis and ethanol-sensing properties. ACS Applied Materials \& Interfaces, 3(12):4689-4694. [doi:10.1021/am201112z]

Wu, X.L., Tan, X.L., Yang, S.T., et al., 2013. Coexistence of adsorption and coagulation processes of both arsenate and NOM from contaminated groundwater by nanocrystallined $\mathrm{Mg} / \mathrm{Al}$ layered double hydroxides. Water Research, 47(12):4159-4168. [doi:10.1016/j.watres.2012.11.056]

$\mathrm{Xu}$, W.H., Wang, J., Wang, L., 2013. Enhanced arsenic removal from water by hierarchically porous $\mathrm{CeO}_{2}-\mathrm{ZrO}_{2}$ nanospheres: role of surface- and structure-dependent properties. Journal of Hazardous Materials, 260:498-507. [doi:10.1016/j.jhazmat.2013.06.010]

Yang, W.H., Lee, C.F., Tang, H.Y., et al., 2006. Iron oxide nanopropellers prepared by a low-temperature solution approach. The Journal of Physical Chemistry B, 110(29): 14087-14091. [doi:10.1021/jp062371t]

Zermane, F., Bouras, O., Baudu, M., et al., 2010. Cooperative coadsorption of 4-nitrophenol and basic yellow 28 dye onto an iron organo-inorgano pillared montmorillonite clay. Journal of Colloid and Interface Science, 350(1): 315-319. [doi:10.1016/j.jcis.2010.06.040]

Zhang, S.W., Xu, W.Q., Zeng, M.Y., et al., 2013a. Superior adsorption capacity of hierarchical iron oxide@magnesium silicate magnetic nanorods for fast removal of organic pollutants from aqueous solution. Journal of Materials Chemistry A, 1(38):11691-11697. [doi:10.1039/c3ta12767b] Zhang, S.W., Li, J.X., Zeng, M.Y., et al., 2013b. In situ synthesis of water-soluble magnetic graphitic carbon nitride photocatalyst and its synergistic catalytic performance. ACS Applied Materials \& Interfaces, 5(23):12735-12743. [doi:10.1021/am404123z]

Zhang, S.W., Li, J.X., Niu, H.H., et al., 2013c. Visible-light photocatalytic degradation of methylene blue using $\mathrm{SnO}_{2} /$ $\alpha-\mathrm{Fe}_{2} \mathrm{O}_{3}$ hierarchical nanoheterostructures. Chempluschem, 78(2):192-199. [doi:10.1002/cplu.201200272]

Zhang, S.W., Zeng, M.Y., Li, J.X., et al., 2014. Porous magnetic carbon sheets from biomass as an adsorbent for the fast removal of organic pollutants from aqueous solution. Journal of Materials Chemistry A, 2(12):4391-4397. [doi:10.1039/c3ta14604a]

Zhao, D.L., Sheng, G.D., Chen, C.L., et al., 2012. Enhanced photocatalytic degradation of methylene blue under visible irradiation on graphene $@ \mathrm{TiO}_{2}$ dyade structure. Applied Catalysis B: Environmental, 111-112:303-308. [doi:10.1016/j.apcatb.2011.10.012]

Zhong, J.Y., Cao, C.B., 2010. Nearly monodisperse hollow $\mathrm{Fe}_{2} \mathrm{O}_{3}$ nanoovals: synthesis, magnetic property and applications in photocatalysis and gas sensors. Sensors and Actuators B: Chemical, 145(2):651-656. [doi:10.1016/j. snb.2010.01.016]

Zhu, H., Jia, Y., Wu, X., et al., 2009. Removal of arsenic from water by supported nano zero-valent iron on activated carbon. Journal of Hazardous Materials, 172(2-3):15911596. [doi:10.1016/j.jhazmat.2009.08.031]

\section{中文橔要:}

\section{本文题目：花状氧化铁的制备及其在废水处理中的应用}

Synthesis of flower-like $\alpha-\mathrm{Fe}_{2} \mathrm{O}_{3}$ and its application in wastewater treatment

研究目的：研究花状氧化铁的制备并探讨其对砷的吸附性能和亚甲基蓝的催化性能。

创新要点: 1. 合成了花状氧化铁; 2. 发现 Langmuir 模型能更好地模拟砷的吸附过程; 3. 发现花状氧化铁 对亚甲基蓝有很好的催化降解性能。

研究方法: 1. 使用扫描电镜、投射电镜、X 射线衍射和 BET 比表面及孔径分析仪对合成的花状氧化铁进 行表征; 2. 采用静态实验法研究砷的吸附性能及亚甲基蓝的催化行为。

重要结论: 1. 采用一种低成本的溶剂热法合成了花状氧化铁; 2. 合成的花状氧化铁有着较大的比表面积 并对砷有着很好的吸附性能, 并且吸附率随着 $\mathrm{pH}$ 的增加而降低。同时发现 Langmuir 模型能 更好地模拟砷的吸附过程; 3. 亚甲基蓝的初始浓度和花状氧化铁的用量对催化性能影响较为 明显, 花状氧化铁有较好的重复利用性; 4. 合成的花状氧化铁可以应用于大批废水的处理。

关键词组: 花状氧化铁; 砷; 吸附; 亚甲基蓝; 光降解 